\title{
DOSES DE NITROGÊNIO E POTÁSSIO NA PRODUÇÃO DE GRAMA ESMERALDA
}

\author{
Nitrogen and potassium rates in the zoysia grass sod production
}

\author{
Leandro José Grava de Godoy ${ }^{1}$, Roberto Lyra Villas Bôas ${ }^{2}$, Clarice Backes ${ }^{3}$,Claudinei Paulo de Lima ${ }^{4}$
}

\begin{abstract}
RESUMO
O nitrogênio e potássio são os nutrientes requeridos em maiores quantidades pelas gramas e no Brasil não se tem informação da quantidade a ser aplicada para se obter a formação de tapete em menor tempo possível. Dois experimentos foram instalados em vasos em casa de vegetação, com o objetivo de avaliar o efeito de doses de nitrogênio e de potássio na produção de tapetes de grama esmeralda (Zoysia japonica). O delineamento utilizado para cada experimento foi fatorial com doses de $\mathrm{N}$ ou $\mathrm{K}$ e épocas de avaliação. Foram aplicadas quatro doses de nitrogênio $\left(0,200,400\right.$ e $\left.600 \mathrm{~kg} \mathrm{ha}^{-1}\right)$ e quatro doses de potássio $\left(0,100,200\right.$, e $\left.300 \mathrm{~kg}^{-1}\right)$. As doses de nitrogênio e potássio foram aplicadas parceladamente em cobertura. O aumento das doses de $\mathrm{N}$ influenciou a taxa de cobertura do solo pela grama (TCS) permitindo a formação do tapete com a dose de $408 \mathrm{~kg} \mathrm{ha}^{-1} \mathrm{de} \mathrm{N}$ aos 198 dias após a colheita do tapete anterior, tempo menor quando comparado com as demais doses. A concentração de $\mathrm{N}$ na folha e da cor verde da grama foram influenciadas pelas doses de $\mathrm{N}$ podendo ser utilizadas para auxiliar na recomendação das doses de $\mathrm{N}$. O aumento das doses de $\mathrm{K}$ não influenciou na TCS pela grama, sendo o teor no solo $\left(1,4 \mathrm{mmol}_{\mathrm{c}} \mathrm{dm}^{-3}\right)$ suficiente para a produção dos tapetes de grama esmeralda.
\end{abstract}

Termos para indexação: Gramado, adubação nitrogenada, adubação potássica, floricultura.

\section{ABSTRACT}

The nitrogen and potassium are nutrients required in bigger amounts by grasses, and in Brazil there is no information about the amount that must be applied to get sod formation in the shortest lesser possible time. Two experiments were carried out in a greenhouse, aiming to evaluate the effect of nitrogen and potassium doses on the Zoysiagrass sod production. The design adopted for each experiment was factorial with doses of $\mathrm{N}$ or $\mathrm{K}$ and times of evaluation. Four nitrogen doses $(0,200,400$ and $600 \mathrm{~kg}$ ha-1) and four $\mathrm{K}_{2} \mathrm{O}$ doses $(0,100,200$, and $300 \mathrm{~kg}$ ha- 1$)$ had been applied. Nitrogen and potassium doses were applied split doses and topdressed. The soil cover rate by the grass (TCS) was influenced by the increase of nitrogen doses allowing the sod formation with $408 \mathrm{~kg}$ ha1 of nitrogen 198 days after the harvest of the previous sod, shorter time when compared to other doses. The $\mathrm{N}$ concentration in the leaf and green color of the grass were influenced by nitrogen doses and could be used to assist in $\mathrm{N}$ doses recommendation. The increase of K doses did not influenced in TCS by the grass, the content in the soil $(1,4 \mathrm{mmolc} \mathrm{dm}-3)$ was enough for the Zoysiagrass sod production.

Index terms: Turfgrass, nitrogen fertilizing, potassium fertilizing ,floriculture.

(Recebido em 5 de junho de 2006 e aprovado em 19 de junho de 2007)

\section{INTRODUÇÃO}

A produção de tapetes de gramas cultivadas no Brasil ocupa cerca de 5 mil hectares, sendo a grama Esmeralda (Zoysia japonica Steud) a principal espécie cultivada (ZANON, 2003).

$\mathrm{O}$ nitrogênio é o elemento mineral requerido em maior quantidade pelas gramas e quando mantido em níveis adequados promove o vigor, qualidade visual e recuperação de injúrias (BOWMAN et al., 2002). O efeito mais conhecido da aplicação do $\mathrm{N}$ em grama é um aumento no crescimento da parte aérea e na intensidade da coloração verde das folhas, além de um ganho no crescimento de raízes e produção de rizomas (CARROW et al., 2001). Entretanto, o excesso de N disponível pode causar um crescimento excessivo da parte aérea e uma redução no crescimento de raízes e rizomas, podendo prejudicar a formação e o corte do tapete (CHRISTIANS, 1998).

O potássio é o segundo nutriente mais extraído pela grama esmeralda e, portanto, a reposição deste nutriente no solo através da adubação é de grande importância, pois a maior parte do K utilizado pela planta é exportada da área de produção com o corte do tapete. Kiesling (1980) em um experimento realizado em um solo com baixos teores de $\mathrm{K}$ verificou que a formação e longevidade de novos rizomas foi diretamente relacionada com a aplicação deste nutriente. Para a grama Zoysia cv. Meyer utilizada nos EUA, pertencente à mesma espécie da grama esmeralda no Brasil,

${ }^{1}$ Professor, Doutor - Universidade Estadual Paulista Júlio de Mesquita Filho/UNESP - Rua Tamekishi Takono, 5, Centro - 11900-000 - Registro, SP _ legodoy@registro.unesp.br

2Professor, Doutor - Departamento de Recursos Naturais Ciência do Solo - Universidade Estadual Paulista Júlio de Mesquita Filho/UNESP - Cx. P. 237 2Professor, Doutor - Departamento de Recursos Naturais
18610-907 - Botucatu, SP - rlvboas@fca.unesp.br

${ }^{3}$ Doutoranda em Agronomia/Horticultura - Departamento de Produção Vegetal/Horticultura - Universidade Estadual Paulista Júlio de Mesquita Filho/ UNESP - Cx. P. 237 - 18610-907 - Botucatu, SP - cbackes@fca.unesp.br

${ }^{4}$ Doutorando em Agronomia/Agricultura - Departamento de Produção Vegetal/Agricultura - Universidade Estadual Paulista Júlio de Mesquita Filho/

UNESP - Cx. P. 237 - 18610-907 - Botucatu, SP - cplima@fca.unesp.br 
o crescimento da parte aérea e dos estolões durante o estabelecimento aumentou com a aplicação de K (JUSKA, 1959).

Sturkie \& Rouse (1967) verificaram coloração verde clara e crescimento lento no início da primavera nos EUA em gramas bermudas e esmeralda quando nenhum $\mathrm{K}$ foi aplicado. Christians et al. (1979) relataram que foi necessário mais $\mathrm{K}$ para maximizar a qualidade da grama bluegrass de Kentucky (Poa pratensis L.) do que para o máximo crescimento. Essa melhoria na qualidade pode estar relacionada com o papel do $\mathrm{K}$ em aumentar a tolerância à seca, ao frio ou ao calor.

De acordo com Turner (1993) a aplicação de K tem mostrado poucos benefícios para o estabelecimento de gramados, e deficiências deste nutriente raramente têm sido observadas ou relatadas nos EUA.

No Brasil, existem recomendações muito simplificadas para a implantação e manutenção de gramados, e que não podem ser extrapoladas para o sistema de produção de grama (GODOY, 2005). Assim, o objetivo deste trabalho foi determinar os efeitos de doses de nitrogênio e potássio na produção de tapetes de grama esmeralda para as condições do Estado de São Paulo.

\section{MATERIAL E MÉTODOS}

O estudo constituiu-se de dois experimentos em casa de vegetação de vidro, com controle de temperatura máxima, em área experimental do Departamento de Recursos Naturais/Ciência do Solo, localizado na Fazenda Experimental Lageado, no município de Botucatu-SP. Utilizou-se vasos de cimento amianto com capacidade para 15 litros $(0,25 \times 0,25 \times 0,24 \mathrm{~m})$, preenchidos com solo classificado como LATOSSOLO VERMELHO Distrófico textura média, de acordo com a Embrapa (1999).

Os vasos foram cultivados com grama esmeralda (Zoysia japonica Steud.) durante um ano e após a cobertura total do solo pela grama, foram cortados tapetes, retirando uma camada superficial de solo, de aproximadamente $1 \mathrm{~cm}$, juntamente com a parte vegetal da grama (rizomas + estolões + raízes + parte aérea), simulando o que ocorre em área de produção quando o tapete de grama é colhido.

A análise do solo apresentou as seguintes características químicas, após a coleta dos tapetes: $\mathrm{pH}$ $\left(\mathrm{CaCl}_{2}\right)$ de 5,8; $16 \mathrm{~g} \mathrm{dm}^{-3}$ de M.O.; $14 \mathrm{mg} \mathrm{dm}^{-3} \mathrm{de} \mathrm{P}$ (resina); 24; 1,$4 ; 26$ e 11 mmol $_{\mathrm{c}} \mathrm{dm}^{-3} \mathrm{de}^{+}+\mathrm{Al}^{+3}, \mathrm{~K}, \mathrm{Ca}$ e $\mathrm{Mg}$, respectivamente; saturação por bases $(\mathrm{V})$ de $62 \%$. A composição granulométrica do solo foi 670,260 e $70 \mathrm{~g} \mathrm{~kg}^{-1}$ de areia, argila e silte, respectivamente. Foi realizada a calagem, com calcário dolomítico (PRNT de 90\%) aplicado em quantidade para elevar a saturação por bases a $80 \%$, e $150 \mathrm{mg} \mathrm{dm}^{-3}$ de solo de $\mathrm{P}$ (1/2 de superfosfato simples e $1 /$ 2 de termofosfato $+\mathrm{S}$, B e $\mathrm{Zn}$ ) na superfície do solo.

O delineamento utilizado para cada experimentos foi fatorial, compreendendo quatro doses de nitrogênio ( 0 , 200, 400, e $\left.600 \mathrm{~kg} \mathrm{ha}^{-1}\right)$ e quatro doses de potássio (0,100, 200 , e $300 \mathrm{~kg} \mathrm{ha}^{-1}$ ) respectivamente e épocas de avaliação, com três repetições por tratamento e cada repetição constituída de três vasos. As épocas de avaliação foram definidas de acordo com as variáveis analisadas para cada experimento. Tanto as doses de nitrogênio quanto as de potássio foram baseadas em quantidades médias utilizadas por produtores de grama do estado de São Paulo, sendo aplicadas sobre a superfície do solo.

No primeiro experimento, as doses de $\mathrm{N}$, utilizando como fonte a uréia, foram parceladas, aplicando $5 \%$ da dose total de cada tratamento, aos 35 dias após o corte do tapete anterior (dac), devido à pequena quantidade de grama cobrindo o solo nesta fase e o restante parcelado em seis aplicações a cada 45 dias (16\% da dose total) em junho, agosto, setembro, outubro, dezembro e janeiro, seguido de irrigação para evitar a queima de folhas. A adubação potássica foi aplicada em cobertura, sendo $200 \mathrm{~kg}$ de $\mathrm{K}_{2} \mathrm{O}$ $\mathrm{ha}^{-1}$, na forma de $\mathrm{KCl}$, aplicando $16 \%$ da dose total aos 35 dac e o restante em três aplicações, a cada 90 dias.

No segundo experimento as doses de potássio foram parceladas aplicando $16 \%$ da dose total de cada tratamento aos 35 dac, utilizando como fonte o $\mathrm{KCl}$ e o restante foi parcelado em três aplicações $(28 \%$ da dose total de cada vez) em setembro, novembro e janeiro. A adubação nitrogenada foi aplicada em cobertura, sendo $400 \mathrm{~kg}$ de $\mathrm{N} \mathrm{ha}^{-1}$, na forma de uréia, utilizando $5 \%$ da dose total aos 35 dac e o restante dividido em seis aplicações, a cada 45 dias.

A irrigação foi realizada através de um regador aplicando, aproximadamente, $0,5 \mathrm{~L}$ de água para cada vaso, a cada 2 dias. A temperatura máxima no interior da casa da vegetação foi controlada para não ultrapassar os $30^{\circ} \mathrm{C}$. As gramas foram mantidas numa altura de $2 \mathrm{~cm}$ através de cortes periódicos utilizando uma tesoura elétrica manual e as aparas foram coletadas.

No experimento com doses de $\mathrm{N}$ foram coletadas amostras da lâmina foliar da grama aos 116, 164 e 239 dac para determinação da concentração de $\mathrm{N}$, e determinação da intensidade da coloração verde das folhas (ICV) da grama, através do clorofilômetro SPAD-502 (Minolta) cuja unidade é denominada SPAD. 
No experimento de adubação potássica, amostras de solo e da lâmina foliar da grama foram coletadas aos 116, 164 e 239 dac, para determinação do teor de $\mathrm{K}$ no solo e na planta, respectivamente. As amostras de solo foram retiradas com um trado de rosca, na profundidade de 20 $\mathrm{cm}$, em três pontos por vaso.

A taxa de cobertura do solo (TCS) pela grama foi avaliada através da análise de imagem digital, conforme metodologia descrita por Godoy (2005), aos 71, 116, 164, 198 e 239 dac, no experimento de adubação nitrogenada e aos 116, 164 e 239 dac no experimento com adubação potássica. As imagens digitais foram obtidas de uma câmera digital Fuji Fine Pix 300, fixada na extremidade de uma estrutura na forma de um "L" invertido. As imagens foram analisadas individualmente utilizando o programa Corel Photo Paint v.10.0. Para o cálculo da TCS pela grama foi dividido o número de pixels verdes pelo número total de pixels da imagem, multiplicado por 100 .

No final do experimento com doses de potássio, oito meses após a implantação, três vasos por tratamento foram selecionados e irrigados até o solo ficar saturado. Estes vasos ficaram sem receber irrigação durante seis dias, período no qual foram pesados diariamente para avaliar a perda de água por evapotranspiração em função das doses de potássio. Como a grama já havia coberto quase que totalmente a superfície do solo a perda de água pode ser considerada como a perda por transpiração. Os resultados de perda de água foram transformados para litros por metro quadrado por dia.

Os resultados foram submetidos à análise variância e de regressão, utilizando o programa Sisvar v. 4.6 (FERREIRA, 2003)

\section{RESULTADOS E DISCUSSÃO}

\section{Experimento com doses de nitrogênio}

Houve interação significativa entre as doses de $\mathrm{N}$ e as datas de avaliação na taxa de cobertura do solo (TCS) pela grama esmeralda (Tabela 1). Aos 71, 116, e 198 dac houve um aumento linear da TCS com as doses de N.

Aos 239 dac houve um ponto de máximo da TCS $(96,19 \%)$ com a dose de $\mathrm{N}$ de $575 \mathrm{~kg} \mathrm{ha}^{-1}$. A TCS pode indicar a velocidade de produção do tapete, uma vez que, a grama esmeralda quando cobre totalmente a superfície do solo, também já produziu rizomas e raízes sob a superfície do solo dando a estrutura para o tapete a ser cortado (CHRISTIANS, 1998).

Aos 198 dac a dose de $\mathrm{N}$ de $408 \mathrm{~kg} \mathrm{ha}^{-1}$ permitiu a formação do tapete de grama esmeralda (TCS de 98\%) em menor tempo em comparação às demais doses e em relação ao tempo médio de 12 meses para a colheita do tapete de grama esmeralda, no Brasil, citado por Pimenta (2003). As gramas que não receberam a adubação nitrogenada e as que receberam $200 \mathrm{~kg} \mathrm{ha}^{-1}$ de $\mathrm{N}$ não formaram tapete, não chegando a cobrir o solo totalmente até o final do experimento (fevereiro). Estes resultados concordam com as citações de Koske (1994) para o estado de Louisiana, EUA, onde o mais rápido crescimento da grama Zoysia sp., para a formação de tapetes, ocorre com a aplicação de $56 \mathrm{~kg} \mathrm{ha}^{-1}$ de $\mathrm{N}$ por mês de crescimento, o que equivaleria a $450 \mathrm{~kg} \mathrm{ha}^{-1} \mathrm{de} \mathrm{N}$, considerando oito meses de crescimento no Estado de São Paulo.

Apesar das pequenas doses adicionadas (5\% da dose total) no início ( 35 dac), aos 71 dac já se pode observar uma diferença na TCS em função das doses de N. As gramas que receberam $24 \mathrm{~kg} \mathrm{~N}^{-1}$ apresentaram uma cobertura de $50 \%$ do solo, enquanto as gramas que não receberam a adubação nitrogenada de base cobriram apenas $12 \%$.

TABELA 1 - Resumo da análise da variância e da regressão da taxa de cobertura de solo pela grama esmeralda em função de doses de N e das épocas avaliadas (Botucatu, SP, 2002/2003).

\begin{tabular}{lccc}
\hline Causa de variação & Quadrado Médio & Regressão & $\mathbf{R}^{2}$ \\
\hline Doses de N & $9154,45^{* * *}$ & -- & -- \\
Época & $3093,12^{* * *}$ & -- & -- \\
Doses x Épocas & $330,76^{* * *}$ & -- & 94,39 \\
Doses dentro de E1 & $887,40^{* * *}$ & $0,0648^{* * *} \mathrm{x}+15,26$ & 96,38 \\
Doses dentro de E2 & $814,92^{* * *}$ & $0,0627^{* * *} \mathrm{x}+14,98$ & 99,41 \\
Doses dentro de E3 & $2663,17^{* * *}$ & $0,0001^{*} \mathrm{x}^{2}+0,0435^{* * *} \mathrm{x}+18,59$ & 96,07 \\
Doses dentro de E4 & $3626,46^{* * *}$ & $0,132^{* * *} \mathrm{x}+21,84$ & 99,88 \\
Doses dentro de E5 & $2485,55^{* * *}$ & $-0,0002^{* * *} \mathrm{x}^{2}+0,23^{* * *} \mathrm{x}+29,94$ & \\
\hline
\end{tabular}

*,** e***: significativo a 5, 1 e 0,1\%, respectivamente. E1, E2,E3, E4 e E5 -Época 1 (71 dac), Época 2 (116 dac), Época 3 (164 dac), Época 4 (198) e Época 5 (239dac). 


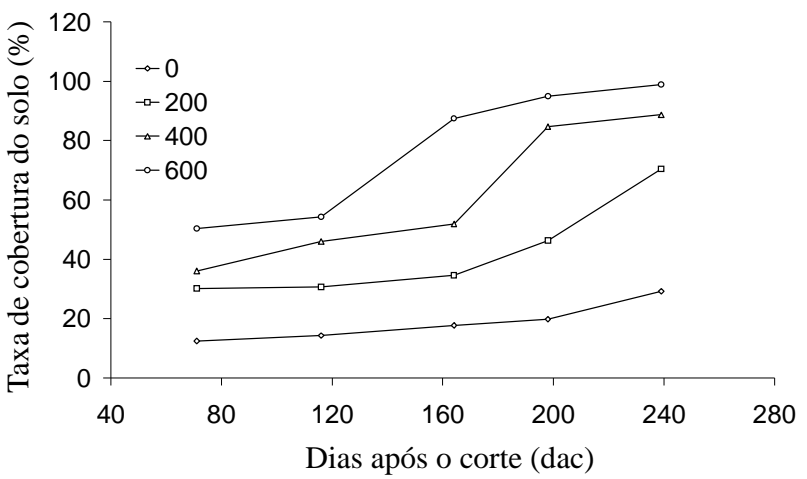

FIGURA 1 - Taxa de cobertura do solo pela grama esmeralda aos 71, 116, 164, 198 e 239 dias após o corte (dac) em função de doses de nitrogênio (Botucatu-SP, 2002/2003).

Dos 71 aos 116 dac não houve alterações significativas na TCS (Figura 1) em função das condições climáticas (baixa temperatura e fotoperíodo mais curto). De acordo com Turfgrass Producers International (2003) não se deve adubar a grama Zoysia até que a temperatura média noturna não atinja $10^{\circ} \mathrm{C}$ ou mais. Assim, vale ressaltar a importância da adubação de base (dose maior ou igual a $24 \mathrm{~kg} \mathrm{~N} \mathrm{ha}^{-1}$ ) em um primeiro arranque no crescimento da parte aérea, principalmente, antes de meses de baixa temperatura e fotoperíodo mais curto.

Aos 198 dac, as gramas que receberam a segunda maior dose de $\mathrm{N}$ apresentaram um crescimento vegetativo (aumento de 34\% na TCS) semelhante ao observado dos 116 a 164 dac (33\%) nas gramas que receberam a maior dose, no entanto, em um menor tempo, devido às altas temperaturas no período. Segundo Carrow et al. (2001) a determinação da época de aplicação e a dose de $\mathrm{N}$ devem ser realizadas quando a grama está em pleno crescimento, o que está relacionado à temperatura. Nas gramas que receberam a maior dose a TCS não aumentou tanto porque já se apresentavam cobrindo cerca de $87 \%$ do solo aos 164 dac.

A concentração de $\mathrm{N}$ na folha da grama esmeralda se ajustou bem às doses de $\mathrm{N}$ aplicadas nas três épocas de avaliação (Tabela 2 e Figura 2a). As gramas que não receberam a adubação nitrogenada apresentaram um teor entre 14 e $16 \mathrm{~g}$ $\mathrm{N} \mathrm{kg}^{-1}$ podendo ser adotado como valor indicativo da deficiência severa de $\mathrm{N}$. Concentração entre 24 e $26 \mathrm{~g} \mathrm{~N} \mathrm{~kg}^{-1}$ determinadas nas gramas que receberam $600 \mathrm{~kg} \mathrm{~N} \mathrm{ha}^{-1}$ podem ser considerados ideais para a produção de tapetes de grama esmeralda, uma vez que as gramas com este teor de $\mathrm{N}$ formaram tapete mais rapidamente. Esta concentração está um pouco acima da faixa considerada ideal por Mills \& Jones Junior (1996), para a grama Zoysia sp. (20 a $\left.24 \mathrm{~g} \mathrm{~kg}^{-1}\right)$. Contudo, duas a três semanas antes da colheita, é recomendável que não seja feita a adubação nitrogenada com fontes solúveis para não elevar a concentração de N na folha. Segundo Darrah \& Powell (1997), altas concentrações de N na planta podem elevar a temperatura nos tapetes enrolados ou empilhados durante a comercialização, devido ao aumento nas taxas de respiração.

A intensidade da coloração verde (ICV) das folhas também foi influenciada pelas doses de $\mathrm{N}$ (Tabela 2, Figura 2b). A máxima ICV foi atingida nas doses de 247,5; $516 \mathrm{e}$ $600 \mathrm{~kg} \mathrm{~N} \mathrm{ha}^{-1}$ aos 71, 164 e 239 dac, respectivamente. Segundo Carrow et al. (2001), quando a dose de N é aumentada a partir de uma condição de deficiência de $\mathrm{N}$, há um incremento no conteúdo de clorofila, proporcionando uma resposta linear quanto à cor verde da grama. Valores de ICV acima de 37 podem ser considerados como adequados para grama esmeralda.

TABELA 2 - Resumo da análise de variância do teor de $\mathrm{N}$ na lâmina foliar e a intensidade de coloração verde da grama esmeralda em função de doses de N e das épocas avaliadas (Botucatu, SP, 2002/2003).

\begin{tabular}{|c|c|c|}
\hline Causa de variação & $\mathrm{N}\left(\mathrm{g} \mathrm{kg}^{-1}\right)$ & ICV (índice) \\
\hline & \multicolumn{2}{|c|}{------------------Quadrado médio (significância)----------------- } \\
\hline Doses de $\mathrm{N}$ & $169,80^{* * *}$ & $163,04^{* * *}$ \\
\hline Época & $13,36^{* *}$ & $4,03^{*}$ \\
\hline Dose x Época & $7,02^{* *}$ & $5,66^{* * *}$ \\
\hline Doses dentro de E1 & $80,97^{* * *}$ & $99,01^{* * *}$ \\
\hline Doses dentro de E2 & $65,00^{* * *}$ & $43,77^{* * *}$ \\
\hline Doses dentro de E3 & $37,88^{* * *}$ & $31,59^{* * *}$ \\
\hline $\mathrm{CV} \%$ & 6,70 & 2,60 \\
\hline
\end{tabular}

*,** e***: significativo a 5, 1 e 0,1\%, respectivamente. ICV - Intensidade da coloração verde. E1, E2 e E3 - Época 1 (116 dae), Época 2 (164 dae) e Época 3 (239 dae). 

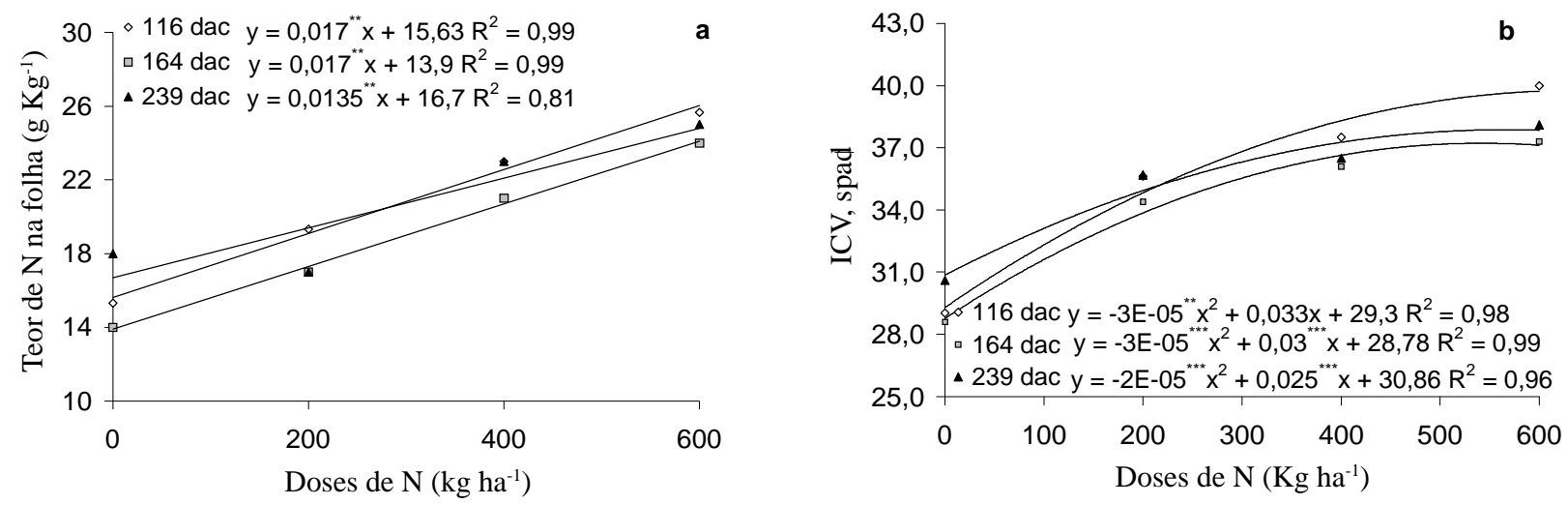

FIGURA 2 - Teor de $\mathrm{N}$ na folha (a) e intensidade de coloração verde da folha (b) da grama esmeralda em função de doses de $\mathrm{N}$ aos 116, 164 e 239 dias após o corte do tapete anterior (dac). (Botucatu-SP, 2002/2003).

\section{Experimento com doses de potássio}

As doses de potássio aplicadas proporcionaram um gradiente do teor de $\mathrm{K}$ no solo de 0,7 a $1,8 \mathrm{mmol}_{\mathrm{c}} \mathrm{K} \mathrm{dm}^{-3}$ no início do ciclo (Tabela 3 e Figura 3).

A amplitude entre os teores de $\mathrm{K}$ no solo foi maior na fase final de produção, variando de 0,5 a $2,6 \mathrm{mmol}_{\mathrm{c}} \mathrm{K}$ $\mathrm{dm}^{-3}$, o que nos permite discutir os efeitos de níveis de $\mathrm{K}$ no solo na produção de grama esmeralda.

Somente a dose de $300 \mathrm{~kg} \mathrm{~K}_{2} \mathrm{O} \mathrm{ha}^{-1}$ permitiu manter o teor de $\mathrm{K}$ no solo acima do teor inicial $(1,4$ $\mathrm{mmol}_{\mathrm{c}} \mathrm{dm}^{-3}$ ) após nove meses de cultivo com a grama esmeralda, uma vez, que as aparas do corte eram coletadas (Figura 3).

$\mathrm{O}$ teor de $\mathrm{K}$ na folha se ajustou bem às doses de potássio aplicadas podendo ser utilizado para auxiliar no manejo da adubação potássica. Aos 116 dac, o teor de K na folha aumentou linearmente com as doses crescentes de K (Figura 3-b).

Aos 164 dac, após a aplicação da segunda parcela da adubação potássica houve um bom ajuste, atingindo um teor máximo de $16 \mathrm{~g} \mathrm{~K} \mathrm{~kg}^{-1}$ na dose de $200 \mathrm{~kg} \mathrm{~K}_{2} \mathrm{O} \mathrm{ha}^{-1}$. No final do ciclo, a tendência do teor de $\mathrm{K}$ na folha também foi o mesmo, no entanto, os teores apresentados foram maiores chegando a $20 \mathrm{~g} \mathrm{~kg}^{-1}$ na maior dose. As plantas que não receberam a adubação potássica mantiveram ainda o teor de $\mathrm{K}$ ao redor de $11 \mathrm{~g} \mathrm{~kg}^{-1}$. Como nenhuma fonte de potássio foi adicionada nestes vasos e as plantas mantiveram um teor de $\mathrm{K}$ na planta ao redor de $10 \mathrm{~g} \mathrm{~K} \mathrm{~kg}^{-1}$, durante oito meses de produção, presume-se que a grama esmeralda seja eficiente na absorção de potássio, uma vez que o teor de $\mathrm{K}$ no solo foi reduzindo de 1,4 para $0,3 \mathrm{mmol}_{\mathrm{c}}$ $\mathrm{dm}^{-3}$, neste tratamento.

Logo, um teor de $1,4 \mathrm{mmol}_{\mathrm{c}} \mathrm{K} \mathrm{dm}^{-3}$ no solo no início de produção dos tapetes permitiu uma produção adequada, sem nenhuma adição de potássio durante o ciclo, no entanto, o $\mathrm{K}$ do solo foi praticamente exaurido o que implicará, provavelmente, numa maior reposição.

Apesar das diferenças observadas do teor de $\mathrm{K}$ no solo e na planta não houve diferença significativa TCS pela grama em função das doses de potássio (Figura 4-a), ou seja, o K não influenciou o crescimento da grama e nem a velocidade de fechamento do tapete. No entanto, o nível de K na planta pode influenciar outras características da planta como a perda de água por transpiração. Este efeito pôde ser observado no final do experimento quando as plantas que receberam a maior dose de $\mathrm{K}$ perderam menos água por transpiração (Figura 4-b), aumentando a eficiência do uso da água pelos gramados, implicando numa diminuição da freqüência de irrigação. 
TABELA 3 - Resumo da análise de variância do teor de K na folha e no solo e da taxa de cobertura de solo pela grama esmeralda em função de doses de K e das épocas avaliadas (Botucatu, SP, 2002/2003).

\begin{tabular}{|c|c|c|c|}
\hline Causa de variação & $\begin{array}{c}\text { Teor de } \mathrm{K} \text { no solo } \\
\left(\mathrm{mmol}_{\mathrm{c}} \mathrm{dm}^{-3}\right)\end{array}$ & Teor de $\mathrm{K}$ na folha $\left(\mathrm{g} \mathrm{kg}^{-1}\right)$ & Taxa de Cobertura $(\%)$ \\
\hline & \multicolumn{3}{|c|}{------------------Quadrado médio (significância)----------------- } \\
\hline Doses de K & $4,33^{* * *}$ & $80,74^{* * *}$ & $27,78 \mathrm{~ns}$ \\
\hline Época & $0,32^{*}$ & $33,26^{* * *}$ & $83977,77^{* * * *}$ \\
\hline Doses x Época & $0,19 \mathrm{~ns}$ & $1,65 \mathrm{~ns}$ & $10,62 \mathrm{~ns}$ \\
\hline Doses dentro de E1 & $0,65^{* * *}$ & $18,30^{* * *}$ & $4,76 \mathrm{~ns}$ \\
\hline Doses dentro de E2 & $2,62^{* * *}$ & $24,33^{* * *}$ & $16,78 \mathrm{~ns}$ \\
\hline Doses dentro de E3 & $1,43^{* * *}$ & $41,41^{* * *}$ & $5,41 \mathrm{~ns}$ \\
\hline $\mathrm{CV} \%$ & 24,47 & 8,86 & 3,28 \\
\hline
\end{tabular}

ns, *, ** e ***: não significativo, significativo a 5, 1 e $0,1 \%$, respectivamente. E1, E2 e E3 - Época 1 (116 dae), Época 2 (164 dae) e Época 3 (239 dae).
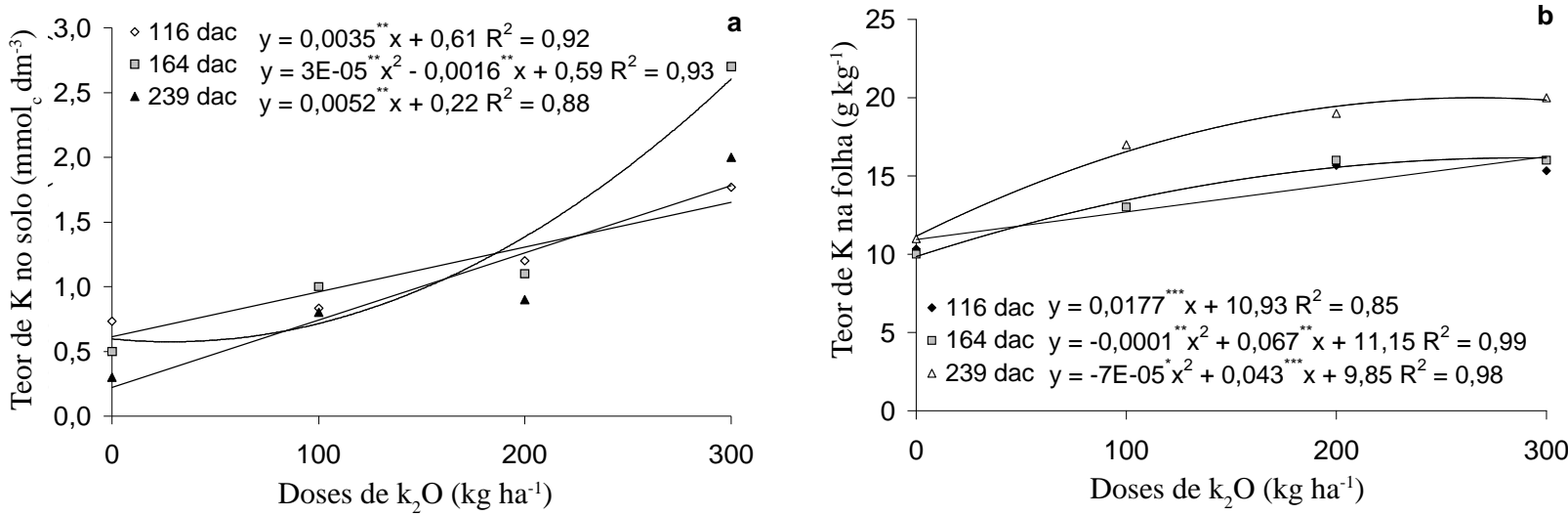

FIGURA 3 - Teor de K no solo (a) e na folha (b) da grama esmeralda em função de doses de potássio aos 116,164 e 239 dias após o corte do tapete anterior (dae) (Botucatu-SP, 2002/2003).
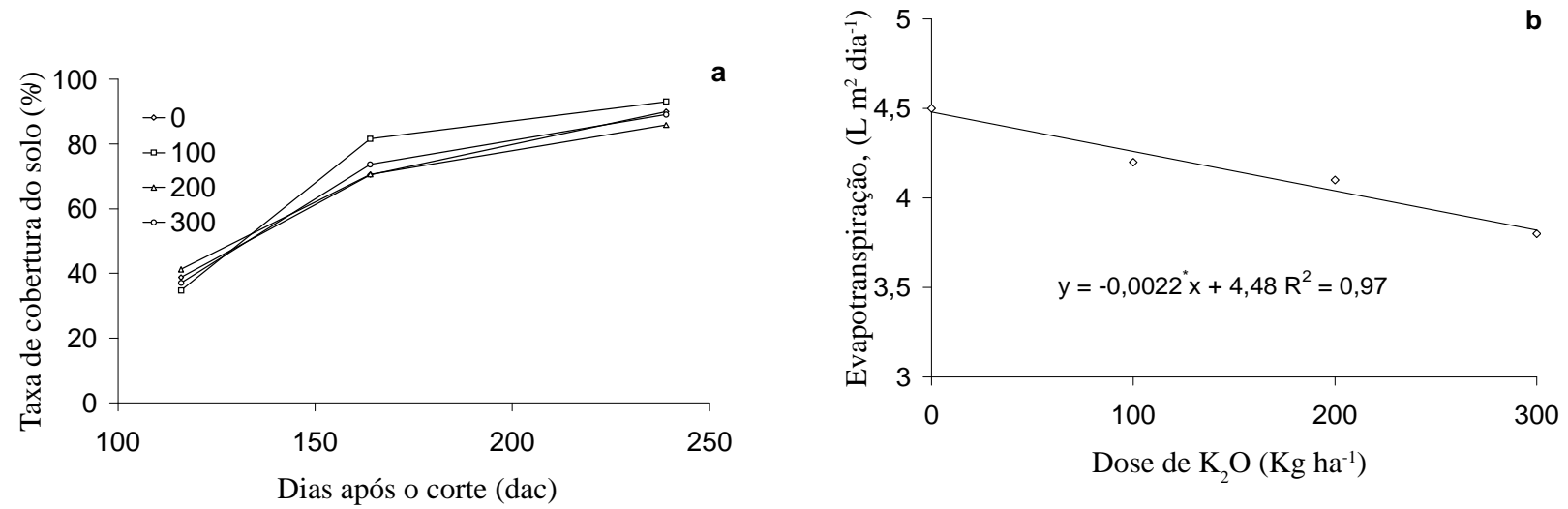

FIGURA 4 - Taxa de cobertura do solo pela grama esmeralda aos 116, 164 e 239 dias após o corte do tapete anterior (a); evapotranspiração (b) em função de doses de potássio (Botucatu-SP, 2002/2003). 


\section{CONCLUSÃO}

$\mathrm{O}$ aumento das doses de $\mathrm{N}$ influenciou a taxa de cobertura do solo pela grama (TCS) permitindo a formação do tapete com a dose de $408 \mathrm{~kg} \mathrm{ha}^{-1}$ de $\mathrm{N}$ aos 198 dias após a colheita do tapete anterior, tempo menor quando comparado com as demais doses.

$\mathrm{O}$ aumento das doses de $\mathrm{K}$ não influenciou na TCS pela grama, sendo o teor inicial encontrado no solo $(1,4$ mmol $\mathrm{dm}^{-3}$ ) suficiente para a produção dos tapetes de grama esmeralda.

\section{REFERÊNCIAS BIBLIOGRÁFICAS}

BOWMAN, D. C.; CHERNEY, C. T.; RUFTY JUNIOR, T. W. Fate and transport of nitrogen applied to six warmseason turfgrasses. Crop Science, Madison, v. 42, p. 833841, 2002.

CARROW, R. N.; WADDINGTON, D. V.; RIEKE, P. E. Turfgrass soil fertility and chemical problem: assessment and management. Chelsea: Ann Arbor, 2001. 400 p.

CHRISTIANS, N. E. Fundamental of turfgrass management. Chelsea: Arbor, 1998. 301 p.

CHRISTIANS, N. E.; MARTIN, D. P.; WILKINSON, J. F. Nitorgen, phosphorus and potassium effects on quality and growth of Kentucky bluegrass and creeping bentgrass. Agronomy Journal, Madison, v. 71, p. 564-567, 1979.

DARRAH, C. H.; POWELL, A. J. Post-harvest heating and survival of sod as influenced by pre-harvest and harvest management. Agronomy Journal, Madison, v. 69, p. 283285, 1997.

EMPRESA BRASILEIRA DE PESQUISA AGROPECUÁRIA. Sistema brasileiro de classificação de solos. Brasília, DF, 1999. 61 p.

FERREIRA, D. F. Sisvar versão 4.2. Lavras: UFLA, 2003.

GODOY, L. J. G. Adubação nitrogenada para produção de tapetes de grama santo agostinho e esmeralda. 2005. $106 \mathrm{f}$. Tese (Doutorado em Agronomia/Agricultura) - Faculdade de Ciências Agronômicas, Universidade Estadual Paulista, Botucatu, 2005.

JUSKA, F. V. Response of Meyer zoysia to lime and fertilizer treatments. Agronomy Journal, Madison, v. 51, p. 81-83, 1959.

KIESLING, T. C. Bermudagrass rhizome iniciation and longevity under differing potassium nutritional levels. Communications in Soil Science and Plant Analysis, New York, v. 11, p. 629-635, 1980.

KOSKE, T. J. Sod production for Louisiana. 1994. Disponível em: <http://www.lsuagcenter.com/en/ lawn_garden/commercial_horticulture/turfgrass/ sod_farming/Sod+Production+in+Louisiana.htm>. Acesso em: 10 dez. 2004.

MILLS, H. A.; JONES JUNIOR, J. B. Plant analysis handbook II: a practical sampling, preparation, analysis and interpretation guide. Athens: MicroMacro, 1996. 456 p.

PIMENTA, C. H. Produção de gramas. In: SIMPÓSIO SOBRE GRAMADOS, 1., 2003, Botucatu. Anais... Botucatu: FCA/UNESP, 2003. CD-ROM.

STURKIE, D. G.; ROUSE, R. D. Response of Zoysia and Tifway Bermuda to $\mathrm{P}$ and $\mathrm{K}$. In: Agronomy abstracts. Madison: American Society of Agronomy, 1967.

TURFGRASS PRODUCERS INTERNATIONAL. Turfgrass: functional, recreational e aesthetic. 2003. Disponível em: <http://www.turgrasssod.org/trc/ statistics.html>. Acesso em: 25 ago. 2004.

TURNER, T. R. Turfgrass. In: BENNET, W. F. (Ed.). Nutrient deficiencies \& toxicities in crop plants. Saint Paul: The American Phytopathological Society, 1993. p. 187-196.

ZANON, M. E. O mercado de gramas no Brasil, cadeia produtiva, situação e perspectiva. In: SIMPÓSIO SOBRE GRAMADOS, 1., 2003, Botucatu. Anais... Botucatu: Unesp, 2003. CD-ROM. 